New evidence indicates that patients with unprotected left main coronary artery (ULMCA) disease who are given drug-eluting stents have improved outcomes compared with those who receive bare-metal stents. Furthermore, survival is significantly improved in the subgroup of patients with distal disease. "Drug-eluting stents significantly improved total survival and major adverse cardiovascular and cerebral event (MACCE)-free survival in patients with distal [ULMCA] disease," explains Pawel Buszman of the Medical University of Silesia, Poland, "despite previous fear that late in-stent thrombosis would occur after drug-eluting stent implantation."

These findings were based on both total survival and MACCEs of 252 patients with ULMCA stenosis. At 4 years of follow-up, the researchers found a significant improvement in MACCEs in participants receiving drugeluting stents as opposed to the baremetal stent group (14.9\% versus $25.9 \%$, respectively). A significantly lower target lesion revascularization rate was also associated with drug-eluting stents (3.2\% versus $10.1 \%$ ), although patients who received these stents did have increased surgical risk and an elevated incidence of diabetes. Additionally, when data from individuals with distal ULMCA disease were analyzed at up to 11 years of follow-up, drug-eluting stents were associated with increased survival.

The investigators predict that these results may instigate a change in ULMCA disease treatment regimes. "We hope that the LE MANS registry [data], together with published randomized and nonrandomized studies, will help to change the guidelines on the treatment of [ULMCA] disease," concludes Buszman, co-developer of the LE MANS program. They next plan to compare ULMCA stenting with CABG in patients with acute coronary syndrome.

\title{
Rowan Higgs
}

